DOI 10.19195/2084-2546.27.18

\title{
MARCIN KUREK
}

ORCID: 0000-0002-7106-0858

Uniwersytet Wroclawski

Correo: marcin.kurek@uwr.edu.pl

\section{"Poema por contacto" como corriente oculta de la poesía moderna}

\author{
Palabras clave: fotografía y literatura - visualidad - Vilém Flusser - Joan \\ Brossa - Vladimir Nabokov.
}

El objetivo de este texto es indicar posibles sentidos de desarrollo de algunas de las ideas expuestas anteriormente en mis estudios sobre la poesia literaria del artista y escritor catalán Joan Brossa ${ }^{1}$. En particular, voy a hacer referencia al concepto de "poema por contacto" interpretado en términos de una analogía semiológica de la fotografía que debemos considerar como técnica y arte modernos por excelencia, siendo probablemente la invención más radical e influyente para la cultura de los últimos dos siglos. En este sentido, es interesante ver si las consecuencias del predominio de los códigos visuales para el desarrollo de la poesía moderna pueden percibirse más bien como una norma — no dominante, pero sí presente — más allá de los experimentos brossianos de carácter vanguardista.

El punto de partida para la hipótesis que quiero abordar es el carácter fundamentalmente visual de toda la civilización moderna y el concepto de la obra (texto literario incluido) como huella de la auténtica presencia del sujeto dentro de la realidad experimentada cada vez más como ininteligible e incoherente ${ }^{2}$. Conforme con el enfoque propuesto, las rupturas estéticas de la modernidad cuya mejor expresión son los movimientos modernistas y van-

${ }^{1}$ M. Kurek, Poesía rasa. La experiencia de lo cotidiano en la lírica de Joan Brossa, Madrid, Visor Libros, 2016.

2 Según observa Jürgen Habermas, "El nuevo valor concedido ahora a lo efímero, lo momentáneo y transitorio, y la celebración concomitante del dinamismo, expresa, precisamente, el anhelo por un presente duradero e inmaculado. Como un movimiento de autonegación, el modernismo es un «anhelo por la verdadera presencia»"; J. Habermas, "Modernidad: un proyecto inacabado", en: J. Habermas, Ensayos políticos, Barcelona, Península, 1988, pp. 267-268. 
guardistas, cuyas propuestas estéticas y filosóficas parecen contradecirse con frecuencia, pueden verse no solo como un eco artístico de la conciencia crítica - es lo que suele ocurrir en la mayoría de los estudios - sino también como reacción intrínseca de las artes (literatura incluida) frente al fenómeno del mimetismo automático y aparentemente ideal, ofrecido por primera vez por las técnicas fotográficas.

Será útil recurrir aquí a la conocida idea del filósofo checo-brasileño Vilém Flusser de dos grandes momentos de ruptura en la historia de la humanidad, aunque me aparte en más de un punto de su visión de la fotografía como primer ejemplo de la "imagen técnica", fabricada por medio de una misteriosa y grave "caja negra" cuyas reglas de funcionamiento desconocemos. Tampoco es mi objetivo entrar en una polémica sobre la naturaleza real de la fotografía que en las últimas tres o cuatro décadas se ha desarrollado en el seno de los estudios estéticos o semiológicos y cuyos extremos van desde la artificialidad hasta la naturalidad totales, es decir desde el cuestionamiento de la dimensión testimonial de cada imagen fotográfica, el enfoque centrado en el carácter científico, técnico, químico o digital del proceso y de sus efectos, hasta la postura idealista expresada quizás mejor por Roland Barthes quien dice: "Sea lo que sea lo que ella ofrezca a la vista y sea cual sea la manera empleada, una foto es siempre invisible: no es a ella a quien vemos" 3 .

Las consideraciones de Vilém Flusser sobre el arte fotográfico parten de la idea de que la civilización humana en toda su historia ha vivido dos momentos cruciales que para siempre cambiaron su destino:

El primero ocurrió alrededor de la última mitad del segundo milenio a. de C., y puede definirse como "la invención de la escritura lineal". El segundo — del cual somos testigos-puede llamarse "la invención de las imágenes técnicas". [...] Dicha hipótesis plantea la posibilidad de que la civilización - y por tanto la existencia humana - esté a punto de sufrir un cambio estructural básico ${ }^{4}$.

Aunque Flusser formule sus comentarios desde la perspectiva de los años ochenta del siglo pasado, de hecho, el invento de la fotografía en el momento de su aparición a nadie deja indiferente. Como es sabido, entre sus críticos más célebres está Charles Baudelaire quien la acusa de satisfacer los gustos más villanos, presagiando de algún modo la época de la omnipresente reproducción, así como la popularidad y la facilidad de la fotografía digital contemporánea:

En esos días deplorables - escribe en 1859 - una industria nueva se dio a conocer y contribuyó no poco a confirmar la fe en su necedad y a arruinar lo que podía quedar de divino en el espíritu francés. Esta multitud idólatra postulaba un ideal digno de ella y apropiado a su naturaleza $[\ldots]$. Un Dios vengador ha atendido a los ruegos de esta multitud. Daguerre fue

\footnotetext{
${ }^{3}$ R. Barthes, La cámara lúcida. Notas sobre la fotografía, Barcelona, Paidós, 1989, p. 34.

${ }^{4}$ V. Flusser, Hacia una filosofía de la fotografia, México, Trillas, 1990, p. 9.
} 
su Mesías. [...] El amor a la obscenidad, que es tan vivaz en el corazón natural del hombre como el amor a sí mismo, no dejó escapar tan buena ocasión de satisfacerse ${ }^{5}$.

Las relaciones mutuas entre la pintura y la fotografía son largas y tan obvias como ambiguas. El nacimiento en torno al año 1840 de la fotografía como capacidad de perpetuar mecánica y automáticamente la imagen proyectada — sabemos que el propio invento de la cámara oscura atribuido a Aristóteles ha sido utilizado por los pintores a lo largo de los siglos como ayuda para el esbozo al natural- desde el primer momento tiene que influir en la actividad pictórica del hombre.

Dicha influencia, también desde el momento de su popularización, se desarrolla de forma paralela por dos vías contradictorias. La producción de imágenes repetibles - igual que la fabricación en serie de pinturas en tubo que pone fin a su elaboración en el taller según las recetas heredadas del maestro- son dos fenómenos que demuestran la influencia de los procesos de modernización económica y tecnológica en el arte. A consecuencia, el artista dotado de talento y de capacidades manuales se ve amenazado, si no impotente, a la hora de competir con la máquina.

El primer grupo de pintores que hace uso práctico de las nuevas aportaciones tecnológicas es el de la Escuela de Barbizon, creada a finales de los años 40, que siguiendo al modelo mimético indicado por el invento de NiépceDaguerre y utilizando pinturas más fáciles de portar, sale del estudio y de la ciudad hacia el campo, creando cuadros "al natural" y a la luz diaria: paisajes, escenas rurales, retratos de personas humildes. La pintura plenarista, desde el primer esbozo hasta el último toque de pincel elaborando el cuadro a la intemperie en contacto directo con el objeto pintado, se asemeja a la fotografía percibida como una huella impresa de la realidad exterior y objetiva. También Gustave Courbet, coetáneo pero independiente del grupo, en los Picapedreros, de 1849, sitúa a sus protagonistas de espaldas al espectador, fundando así la pintura moderna con su tema trivial, mundano, comprometido con el esfuerzo de los obreros anónimos. Y en su conocida Lettre aux jeunes artistes de Paris, publicada en 1861, escribe: "la peinture est un art essentiellement concret et ne peut consister que dans la représentation des choses réelles et existantes. C'est une langue toute physique, qui se compose, pour mots, de tous les objets visibles". Cuando quince años más tarde pinta su escandaloso Origen del mundo, copia ya directamente, según estudiosos de su obra, una de las fotografías pornográficas de Auguste Belloc ${ }^{6}$.

Curiosamente, esta primera generación de realistas sirve de inspiración directa para el impresionismo, es decir el último movimiento figurativo situado a caballo entre la pintura tradicional y el experimentalismo de las vanguardias.

Como con acierto resume André Rouillé en su libro La photographie. Entre document et art contemporain, los pintores de la segunda mitad del

\footnotetext{
${ }^{5}$ Ch. Baudelaire, Salones y otros escritos sobre arte, Madrid, Machado Libros, pp. 231-233.

${ }^{6}$ K. Taylor, "Courbet's Eye and the Camera", The Sun, 25 de febrero de 2008.
} 
siglo XIX en su práctica reaccionarán al fenómeno fotográfico de dos maneras: "o intentarán imitar lo que hace el oponente, y concretamente la fotografía, o se ocuparán de un área totalmente distinta, introduciendo la pintura en zonas inaccesibles para la fotografía"7. Estas zonas serán las abiertas por Cézanne, Gaugin, Touluse-Lautrec, Van Gogh y continuadas por Munch, Picasso, Malevich, etcétera.

El impresionismo se dirige hacia lo existente, lo de aquí y ahora, muchas veces fragmentado, rechazando los ideales estéticos y mitológicos de la pintura clásica y clasicista pero también la romántica, dejando a la luz penetrar libremente en el cuadro, igual que hace en la fotografía. Conjuntamente, dice Rouillé, "el impresionista y el fotógrafo introducen nuevas imágenes, apostando por una visión moderna de la verdad que consiste en captar la realidad

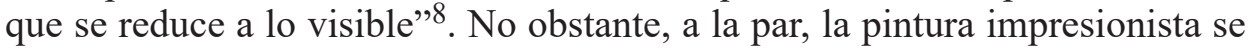
protege ante el acoso realista de la fotografía, por eso sus toques, vistos desde cerca, parecen algo inacabado, no lineal, lo cual la opone tanto a la pintura realista, como al producto industrial y al detalle fotográfico. La cualidad de no acabado nos remite, por su parte, al concepto de la obra abierta, la no definitiva, que encuentra su significado en el receptor, espectador, lector, oyente. La pintura que ofrece imágenes fragmentarias de lo visible pero que al mismo tiempo no oculta su cualidad de artefacto: ésta es la paradójica situación del movimiento artístico que se constituye en el mismo umbral de la modernidad. Como advierte Adorno, "cuando nos imaginamos que agarramos los detalles de la obra de arte, éstos se nos deshacen en algo indeterminado e imposible de diferenciar: hasta ese punto son intermediarios" $"$. De manera muy característica, lacónica e ingeniosa, esa misma observación la convierte Joan Brossa en un poema sintético del libro El saltamartí:

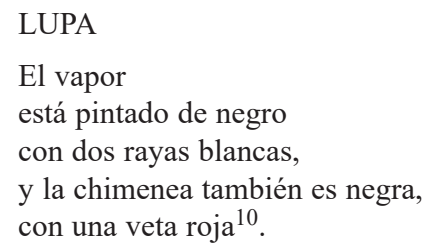

La propia etimología de la palabra "fotografía" que designa este arte moderno por excelencia se basa en el verbo graphein, que tanto nos remite a la actividad de dibujar o grabar como a la de escribir, ambas por medio de la luz. Obviamente, incluso un rápido esbozo histórico de las relaciones mutuas entre la fotografía y la literatura como tal excedería los límites de este texto. La

${ }^{7}$ A. Rouillé, Fotografia. Między dokumentem a sztuka wspótczesna, Kraków, Universitas, 2007, s. 334 (traducción de polaco es mía).

${ }^{8}$ Ibidem, p. 336.

9 T.W. Adorno, Teoría estética, Madrid, Akal, 2004, p. 179. Serraller.

10 J. Brossa, Poemes de seny $i$ cabell, Barcelona, Ariel, 1977, p. 764. Traducción de Amelia 
analogía fotográfica que he identificado en una de las modalidades líricas practicadas por Joan Brossa con especial intensidad - aunque con mayor o menor frecuencia presente también en otros poetas: hispánicos, anglosajones, polacos - es, en mi opinión, efecto de un proceso de reflexión crítica en torno a la lengua en cuanto herramienta mediatizadora y generalizadora, insuficiente para la expresión de la experiencia individual.

Como dice Rouillé, a propósito del descubrimiento de ready-made hecho por Marcel Duchamp - recordemos que en las encuestas realizadas entre los críticos y artistas en torno al año 2000, su obra Fuente ha sido considerada como la más influyente del pasado siglo ${ }^{11}$ — el choque provocado por el invento fotográfico no estaba motivado por el temor ante la nueva competencia (aunque sí, por lo general, el fotógrafo del pueblo sustituyó al retratista), sino ante el cambio que suponía para todo el sistema del arte. Con la fotografía, se suprime la obra como efecto de trabajo manual del artista, dejan de contar sus conocimientos, desaparece el contacto físico del autor con el objeto creado: lo que hace el fotógrafo es seleccionar un fragmento de la realidad y recortar la imagen.

Mientras el cuadro es fruto final de un largo proceso de creación y efecto de conversión de materiales básicos (colores) en un objeto único, el ready-made en cambio, igual que la fotografía, parte de otro punto, desde un objeto existente, a menudo banal y prosaico [...] para convertirlo en una obra de arte mediante un doble proceso que consiste en la selección realizada por el artista y la aceptación por parte de la institución artística. La transformación material que efectúa el pintor es sustituida en ready-made por una transformación simbólica, una conversión específica. No todo es arte, pero todo puede llegar a serlo o más bien cada cosa puede llegar a ser materia artística, siempre y cuando se inscriba en un proceso artístico ${ }^{12}$.

La fotografía y el ready-made comparten también otra característica: la de ser prueba, documento, huella física de una realidad histórica y objetiva que se nos revela sin mediación de un código pictórico o la lengua. El desarrollo de una de las poéticas brossianas — hablo de las poéticas en plural porque la tipología de textos escritos por el artista catalán, autor de más de cien libros de poesía, abarca también otras formas como el soneto, la oda o la sextina- en gran medida está inspirado por la creciente desconfianza con las posibilidades comunicativas del idioma e incluye el desenmascaramiento irónico de lo convencional y lo arbitrario del código, varios intentos de dislocar y ampliar sus significados y la paulatina deconstrucción o depuración del poema de elementos "artificiales" como normas estróficas, metáforas, reflexiones, en favor de la narración pura, del lenguaje coloquial, más tarde, a favor de lo sintético de la palabra suelta y, finalmente, de la cita, de la reproducción de la escritura a mano, de la fotografía y hasta de objetos ajenos (p. ej. una servilleta) incluidos dentro del libro a manera de ready-made.

11 "Un urinario, la obra de arte más influyente del siglo XX", El País, 4 de diciembre de 2004.

12 A. Rouillé, op. cit., pp. 341-342. 
Aludiendo al título a uno de los libros de Brossa, he denominado este complejo proceso como "poesía rasa", centrada en expresar la verdadera experiencia de sujeto en contacto directo con los elementos - vivos y muertos- del mundo observado. El autor catalán parte del poema de verso libre que ofrece meras descripciones de escenas callejeras, utilizando un lenguaje simple, desprovisto de figuras retóricas, en el que predominan sustantivos y verbos, que a modo de relatos fílmicos o acotaciones teatrales reproduce escenas en movimiento, adoptando la perspectiva de un objetivo fílmico. El desarrollo que experimenta la poética brossiana tiene carácter claramente visual. También, a partir de entonces, comienza un proceso de progresiva "esencialización" estructural y lingüística en el que los poemas quedan simplificados a textos de unas pocas y hasta de una sola palabra.

Veamos este ejemplo, con un título tan significativo en el contexto que nos interesa:

\section{DOS FOTOGRAFÍAS}

El edificio tal y como estaba antes del incendio.

Después del incendio y de la guerra ${ }^{13}$.

Lo que sorprende en este escueto poema es que no aporta ningún tipo de descripción de las imágenes evocadas por el sujeto lírico claramente escondido. Se habla de un edificio cuyos detalles desconocemos por completo y las dos frases que integran el texto se asemejan a un pie de foto: puede tratarse de dos fotografías publicadas en un periódico o un libro. Brossa construye aquí una interesante y contradictoria relación entre el verso que leemos y las imágenes mencionadas a las que no tenemos acceso: la palabra, para que el lector pueda darle algún sentido, necesariamente requiere un complemento visual. De este modo los significantes - las dos fotografías manejadas por el sujeto y el texto del poema - se identifican con la realidad objetiva situada más allá.

Otro poema, sin título, dice solamente:

\section{Guante.}

Mano ${ }^{14}$.

Las dos palabras chocan con su presencia puntual. Ambos sustantivos, como elementos del sistema, remiten a los conceptos abstractos, pero también a un objeto que conocemos personalmente y a una parte del cuerpo con la que solemos tocar el mundo físico. En los textos extremadamente sintéticos como éste, el poema de Brossa aprovecha al máximo su condición de shifter: el símbolo indexicalizado, una unidad lingüística, cuyo significado está siempre relacionado con un enunciado particular. Como signo indexical que señala el hecho único e irrepetible relacionado con la vivencia del sujeto, el poema

13 J. Brossa, Poemes Civils. Poemas Civiles, Madrid, Visor, 1990, p. 259.

14 Ibidem, p. 159. 
denota un suceso existencial subjetivo. El lector no ha sido su testigo -igual que no ha vivido lo que representa una foto ajena- pero acepta su carácter de signo que mediante la relación real de su existencia individual se relaciona con el objeto concreto: nos remite al referente, lo indica. Si aceptamos la tesis heideggeriana de que nuestro existir en el mundo se produce por mediación de los objetos, el poema integrado por dos sustantivos aislados, es decir depurado hasta "el objeto", nos sitúa de nuevo en la realidad mediatizada por la lengua.

El significado ontológico de la fotografía en cuanto una prueba de la realidad se vincula con la práctica poética de Brossa a través de su manera de generar las imágenes. La poesía de lo cotidiano, centrada en la narración banal, recuerda a un guión fílmico o una acotación teatral, evocando series de escenas representadas. El poema sintético, compuesto de palabras sueltas, a menudo meros sustantivos, pretende suprimir la mediatización del sistema: sus elementos ya no hacen referencia a conceptos abstractos, sino señalan la existencia histórica de objetos reales.

No obstante, hay en la obra de Brossa otra modalidad de relación entre lo visual y lo lingüístico, una especie de doble juego en el que el escritor con el uso de palabras - recurso necesariamente mediatizador - reproduce otra relación, la física y espacial, recreando las circunstancias en las que se encuentran los objetos observados por el sujeto. Veamos este ejemplo:

\title{
BIGOTE
}

\author{
Me miro en un espejo de mano \\ donde están pintados \\ unos bigotes, \\ y procuro que las rayas \\ me queden encima \\ del labio superior ${ }^{15}$
}

El poema, escrito en 1963, a modo de otros textos del autor concebidos en dicha década, renuncia a la descripción o la reflexión para relatar en presente una situación banal: el personaje utiliza un espejo modificado - una suerte de ready-made - para ver su rostro en una posición determinada. Reproduciendo el juego visual en el que participa el artefacto y la cara reflejada, Brossa traslada al nivel del texto literario la relación óptica que en el mundo real se establece entre el ojo y el objeto. La verosimilitud de una situación vivida es reforzada por su dinamismo: el espejo en la mano se mueve y el sujeto procura ajustar el bigote pintado al reflejo del fondo. En realidad, lo que reproduce el texto es una sucesión de movimientos, como si viéramos una escena grabada con los ojos de quien narra ${ }^{16}$.

15 J. Brossa, Poemes de seny i cabell..., p. 704. Traducción de Amelia Serraller.

${ }^{16}$ Este sencillo poema no deja de sorprender también por la riqueza de asociaciones que despierta a nivel intertextual: el bigote dibujado y el espejo invocan por ejemplo a L.H.O.O.Q. de Marcel Duchamp, el bigote de Salvador Dalí e incluso el juego de reflejos de Diego de Velázquez retratado en Las Meninas con bigote y un espejo. 
El que este tipo de codificación literaria-visual que acabamos de ver no sea un caso aislado sino, tal vez, el ejemplo de una corriente más profunda presente en la literatura moderna, lo comprueba la siguiente cita. En la primera estrofa del poema extenso Pálido fuego, del ficticio poeta estadounidense John Shade, protagonista de la novela homónima de Vladimir Nabokov, de 1962, leemos:

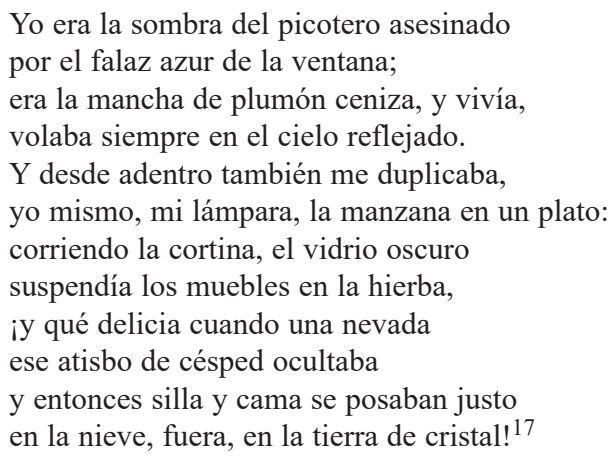

La ilusión óptica, la concentración en el detalle y la sorprendente compenetración del mundo exterior (jardín, césped nevado) e interior (muebles de la habitación) abren el espacio físico y real hacia una dimensión paradójica o mágica de un mundo al revés que a modo de un objeto surrealista o un collage une elementos heterogéneos para producir efectos inesperados, cuestionando así nuestros hábitos interpretativos y el automatismo de la percepción ${ }^{18}$. La imagen evocada, en el contexto de todo el poema y de la novela que constituye su comentario, nos dirige también hacia la misteriosa problemática abordada por Nabokov: la vida póstuma. Por otra parte, le estrofa citada, como el poema brossiano, reproduce un fenómeno visual que reconocemos como una posible experiencia cotidiana, aunque requiera que aparezca una determinada serie de elementos: la tarde de invierno, los objetos iluminados por una lámpara y reflejados en la ventana, la nieve que resplandece en la oscuridad. El texto poético, al incitar a un juego propio de los recursos visuales, reformula su condición de una obra mediatizada por un código abstracto y sigue el camino abierto por las imágenes técnicas.

Ahora bien. Rouillé, con todas las objeciones que formula respecto al carácter objetivista y documental de la fotografía, considera que, si podemos hablar de una verdad contenida en la imagen fotográfica, ésta

resulta no tanto de su afinidad con el objeto, sino del propio contacto que se crea entre ellos. Podemos hablar por tanto de una nueva fórmula de la verdad que se genera en mayor grado gracias al contacto físico y no a la semejanza. En la terminología de Pierce la verdad es más

\footnotetext{
${ }^{17}$ V. Nabokov, Pálido fuego, Barcelona, Anagrama, 2003, p. 17.

18 Cfr. M. Kurek, op. cit., pp. 56-61.
} 
indexical que icónica. La huella predomina sobre la mimesis. O más bien la mimesis describe, mientras que la huella da $\mathrm{fe}^{19}$.

Al cuestionar la objetividad de la imagen técnica, Flusser va más allá de cualquier pretensión documental de la fotografía y dice que el fotógrafo:

trata de establecer situaciones que no han existido; no busca situaciones en el mundo "exterior": ese mundo no es sino el pretexto para establecer las situaciones improbables propuestas [...]. Lo que tenemos, entonces, es una inversión del vector de significación: no es "real" lo significado, sino lo significante, la información, el símbolo ${ }^{20}$.

Esta misma limitación es aplicable al estatus del poema por contacto. El texto escrito, sea un relato a modo de acotación o una palabra aislada que indica a un objeto exterior, no deja de ser intermediario hecho de signos que necesariamente ha de servir como prueba única. La lucha continua entre la imagen y la escritura que, según Flusser, caracteriza toda la historia humana, demuestra que el pensamiento imaginativo es menos abstracto que el conceptual.

Al inventar la escritura, el hombre se alejó aún más del mundo [...]. La finalidad de la escritura es mediar entre el hombre y sus imágenes; explicarlas. Al hacerlo, los textos se interponen entre el hombre y la imagen: le ocultan el mundo al hombre en vez de hacérselo más inteligible ${ }^{21}$.

En definitiva, el gesto del artista que con un poema por contacto parece indicar a entes reales o absorber un fragmento de la realidad, desempeña el mimo papel que el del fotógrafo. "En resumen - dice Flusser- la intención del fotógrafo es hacerse inmortal en la memoria de otras personas, informando a esas personas mediante las fotografías" 22 . No es otra la intención de todo artista que levanta el edificio de su obra, como toda la cultura, en contra del olvido y la muerte: dar fe de su presencia mediante la huella real que deja su obra.

\section{Referencias bibliográficas}

\section{Libros}

ADORNO Theodor

2004 Teoría estética, trad. J. Navarro Pérez, Madrid, Akal.

BARTHES Roland

1989 La cámara lúcida. Notas sobre la fotografía, trad. J. Sala Sanahuja, Barcelona, Paidós.

\footnotetext{
19 A. Rouillé, op. cit., p. 103.

${ }^{20}$ V. Flusser, op. cit., p. 36.

${ }^{21}$ Ibidem, pp. 13-14.

22 Ibidem, pp. 42-43.
} 
BAUDELAIRE Charles

2017 Salones y otros escritos sobre arte, trad. C. Santos, Madrid, Machado Libros.

BROSSA Joan

1977 Poemes de seny $i$ cabell, Barcelona, Ariel.

1990 Poemes Civils. Poemas Civiles, trad. José Batlló, Madrid, Visor.

FLUSSER Vilém

1990 Hacia una filosofía de la fotografía, trad. E. Molina, México, Trillas. HABERMAS Jürgen

1988 Ensayos políticos, Barcelona, Peníncula.

KUREK Marcin

2016 Poesía rasa. La experiencia de lo cotidiano en la lírica de Joan Brossa, trad. J. Nowicka, A. Serraller, Madrid, Visor Libros.

NABOKOV Vladimir

2003 Pálido fuego, trad. A. Bernárdez, Barcelona, Anagrama.

ROUILLÉ André

2007 Fotografia. Między dokumentem a sztuka wspótczesna, trad. O. Hedemann, Kraków, Universitas.

\section{Artículos}

S.A.

2004 "Un urinario, la obra de arte más influyente del siglo XX", El País, 4 de diciembre.

TAYLOR Kate

2008 „Courbet's Eye and the Camera”, The Sun, 25 de febrero.

\section{"Contact poem" as a hidden current of modern poetry}

Keywords: photography and literature — visuality — Vilém Flusser — Joan Brossa Vladimir Nabokov.

\section{Abstract}

The aim of this text is to indicate possible senses of development of some of the ideas exposed previously in my studies on the literary poetry of the Catalan artist and writer Joan Brossa. In particular, I refer to the concept of "contact poem" interpreted in terms of a semiological analogy of photography that we consider as a modern technique and art par excellence, being probably the most radical and influential invention for culture of the last two centuries. In this sense, it is interesting to see if the consequences of the predominance of visual codes for the development of modern poetry can rather be perceived as a norm beyond the Brossian experiments of an avant-garde nature.

Following a theoretical approach based on the ideas of V. Flusser and A. Rouillé, some of Brossa's texts are analysed from the perspective of visualisation techniques and linked to another literary example, the novel Pale Fire by V. Nabokov.

Fecha de recepción: 5.02.2019

Fecha de aceptación: 27.08.2019 